\title{
POLÍTICA HABITACIONAL E LOCAÇÃO SOCIAL EM CURITIBA
}

\author{
Tomás Antonio Moreira*
}

\begin{abstract}
A partir de dados censitários, o artigo analisa a política habitacional de interesse social na Região Metropolitana de Curitiba, entre 2000 e 1010. Os dados sobre os fluxos migratórios revelam que, embora essa região atraia maior número de migrantes no estado, já não é para a capital que se dirige a maioria. As cidades de São José dos Pinhais e Colombo, dotadas de menor infraestrutura, constituem o maior polo de atração. Com foco em habitação para famílias de baixa renda, o aluguel social em especial, são apresentadas as condições das unidades habitacionais, a infraestrutura disponível e os aspectos demográficos e socioeconômicos dos chefes de família. A leitura dos dados é contextualizada por uma recuperação histórica das políticas habitacionais promovidas pelo Estado desde a década de 1970.
\end{abstract}

PALAVRAS-CHAVE: Política habitacional. Locação social. Fluxos migratórios. Região Metropolitana. Curitiba.

\section{COMPORTAMENTO DEMOGRÁFICO DO MUNICÍPIO DE CURITIBA}

Entre 2000 e 2010, a população de Curitiba aumentou em pouco mais de 165 mil habitantes. $\mathrm{O}$ município que, em 2000, possuía 1.586.848 habitantes passou a abranger 1.751.907 habitantes, em 2010. Segundo um levantamento feito pelo Departamento Intersindical de Estatística e Estudos Socioeconômicos, se continuar nesse ritmo, em 2013 serão quase dois milhões de pessoas morando no município de Curitiba. Dados similares foram apresentados pelo Ministério das Cidades, delineando o ritmo de crescimento para 2013, 2017 e 2021 (Brasil. Ministério das Cidades, 2012, 2014).

* Professor Titular da Pontifícia Universidade Católica de Campinas. Ph.D. em Estudos Urbanos pela Université du Québec à Montréal.

Rodovia D. Pedro I, km 136. Campus I - Programa de Pós-Graduacão em Urbanismo (Prédio H-14). Parque das Universidades. Cep: 13086-900. Campinas - São Paulo Brasil. tomas_moreira@hotmail.com
Gráfico 1 - Evolução populacional de Curitiba

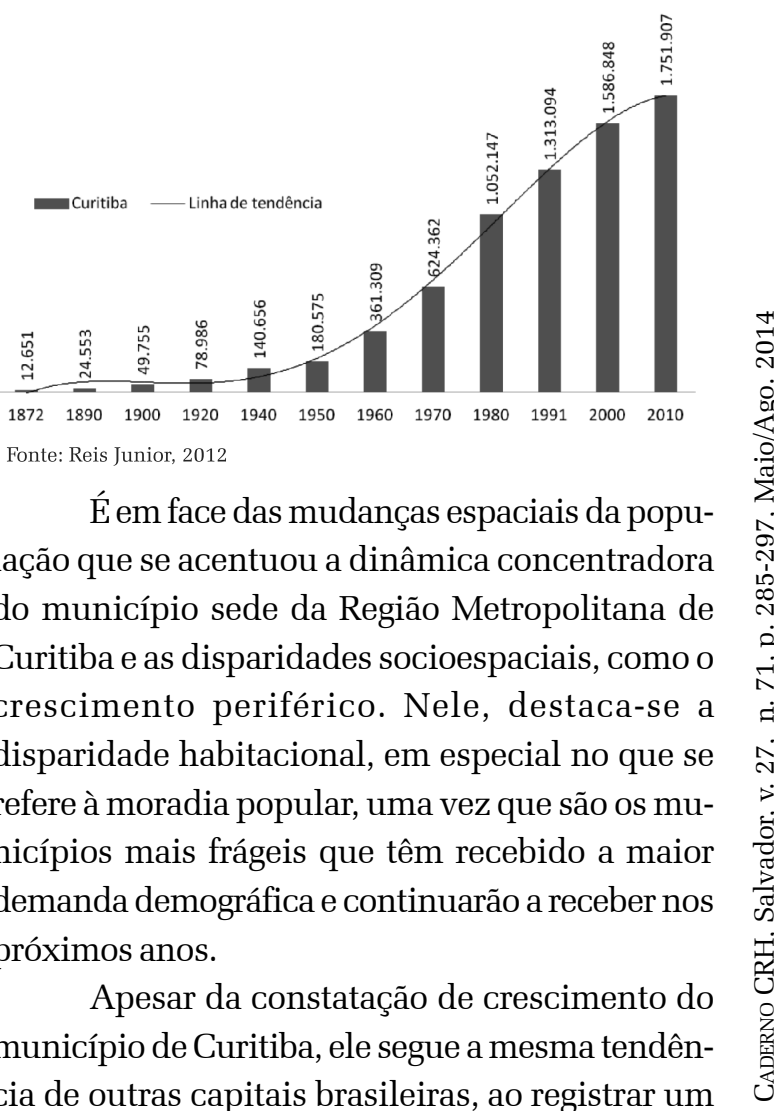


crescimento apenas vegetativo, não sendo mais um grande polo de atração de fluxo migratório. Mesmo não sendo polo de atração, a Região Metropolitana de Curitiba ainda o é, mas são os municípios do núcleo central dessa região que passam a se constituir como polos de atração. São José dos Pinhais e Colombo são dois desses municípios. Entre 2007 e 2008, a população de São José dos Pinhais aumentou em quase de 10 mil habitantes. $\mathrm{O}$ município que, em 2007, possuía 263.622 habitantes passou a abranger 272.530 habitantes em 2008. O acréscimo, nesse período, foi de 3,38\%, quase o dobro do acréscimo constatado no município de Curitiba. O crescimento desde os anos 80 já era praticamente o dobro do município-sede. A taxa de crescimento, em 1980, era de 5,51 contra 2,90; em 1991, era de 5,81 contra 2,34; em 2000, era 4,85 contra 1,83. Essa tendência se repetiu. $\mathrm{Na}$ mesma lógica, verifica-se que, entre 2007 e 2008, o município de Colombo, cresceu, da mesma maneira, em quase de $10 \mathrm{mil}$ habitantes. O município que, em 2007, tinha 233.916 habitantes passou a apresentar 241.505 habitantes em 2008. O aumento, nessa ocasião, foi de 3,24\%, quase o dobro da ampliação constatada no município de Curitiba. O crescimento desde os anos 80, para esse município, também já era praticamente o dobro do município-sede. A taxa de crescimento, em 1980, era de 5,87 contra 2,90; em 1991, era de 5,47, contra 2,34; em 2000 era 4,51 contra 1,83. Essa tendência se repetiu e também é perceptível nos municípios de Piraquara e Campina Grande do Sul (Moreira; Leonelli; Nascimento Neto, 2012)

Essa nova atração, segundo Rosana Baeninger, já é resultado das transformações ocorridas na década de 1990, em especial no que diz respeito à diminuição dos saldos migratórios bem como um menor volume

de emigrantes interestaduais. Desta- Fonte: Autor, Base COMEC, 2009 que maior fica para os movimentos migratórios urbanos-urbanos, em especial para região sudeste e sul do país. Para o Paraná constatou-se uma migração urbana-urbana da ordem de 1.092.667 habitantes, o que representou $56,4 \%$ de todos os fluxos migratórios (Baeringer, 2003).

Essa nova atração também é reflexo das novas dinâmicas ocorridas na década de 2000, quando as regiões metropolitanas ainda eram polos de atração, mas não mais os municípios-sede, e sim os municípios que as compõem e, em muitos casos, os mais frágeis socialmente. Não apenas São José dos Pinhais e Colombo têm sido polos de atração e destino dos novos fluxos migratórios, sejam eles urbanos-urbanos ou rurais-urbanos, o que, no Paraná, ainda corresponde a 20\% do total de fluxos.

Segundo dados do Ministério das Cidades bem como do Instituto Paranaense de DesenvolviFigura 1 - Principais municípios com crescimento populacional elevado, médio e baixo da Região Metropolitana de Curitiba

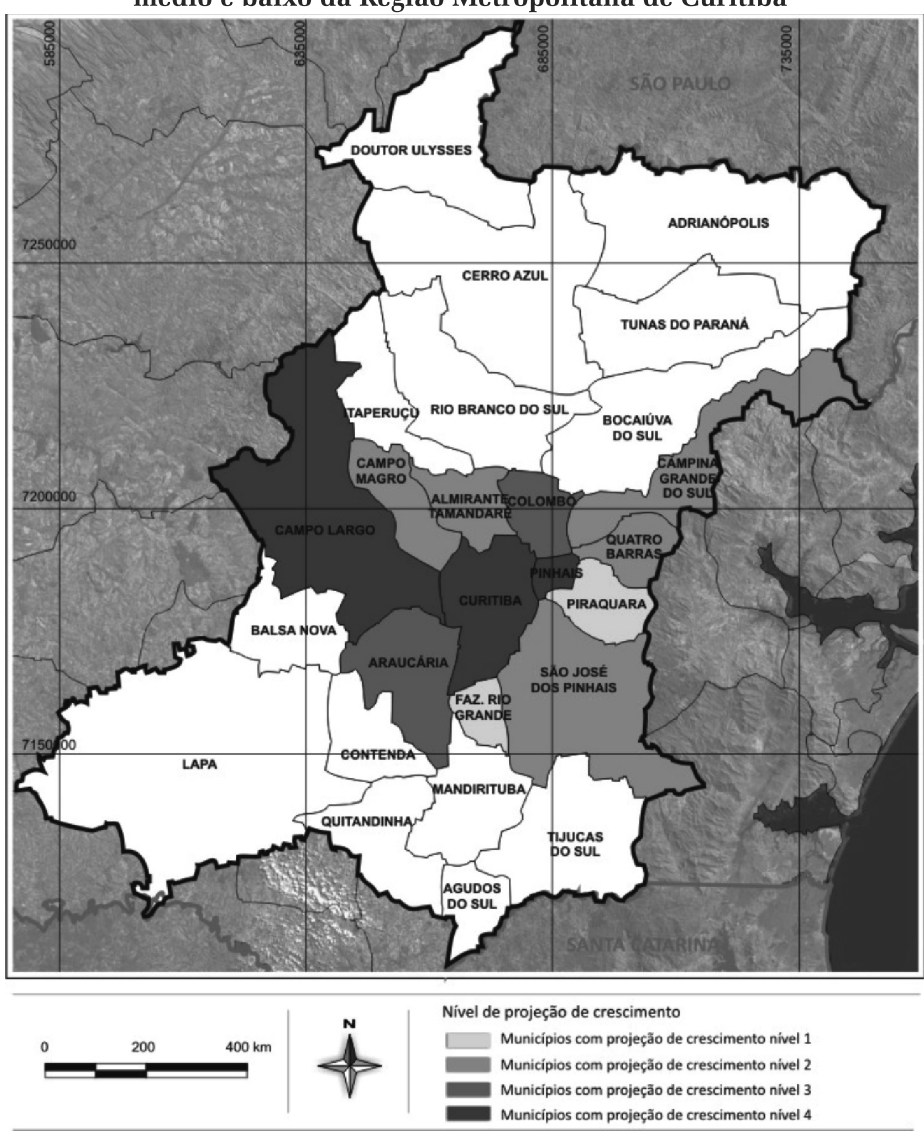


mento Econômico e Social (IPARDES), a Região Metropolitana de Curitiba chegará a quase 5 milhões de habitantes, em 2020. De acordo com os estudos do IPARDES (Brembatti, 2007), a Região Metropolitana de Curitiba deverá obter incremento populacional da ordem de mil habitantes por ano. Contudo, desses, apenas 37 mil habitantes estarão no município de Curitiba, pois a maioria terá como destino os demais municípios. Dos 26 municípios que compõem a Região Metropolitana de Curitiba, apenas 12 deles serão responsáveis pelo aumento demográfico até 2020.

Dentre os municípios da Região Metropolitana de Curitiba, destacam-se: os municípios com projeção de crescimento nível 1, acima de 200\%, Piraquara e Fazenda Rio Grande; os municípios com projeção de crescimento nível 2, entre 100 e 200\%, São José dos Pinhais, Almirante Tamandaré, Campina Grande do Sul, Campo Magro e Quatro Barras; os municípios com projeção de crescimento entre 50 e $100 \%$, Colombo e Araucária; e os municípios com projeção entre 10 e 50\%, Campo Largo, Pinhais e Curitiba (Brembatti, 2007). Esses municípios fazem parte no, Núcleo Urbano Central da Região Metropolitana de Curitiba (NUC), composto por esses 12 municípios, além de Itaperuçu e Rio Branco do Sul.

\section{POLÍTICAS HABITACIONAIS NO MUNICÍPIO DE CURITIBA}

A primeira política habitacional na cidade de Curitiba foi uma resposta à formação de favelas e ocupações irregulares, que ocorreu entre os anos 1940 e 1960, com o apoio da política nacional de habitação. A política implantada na cidade foi de desfavelamento e transferência da população moradora em áreas de favelas ou ocupações irregulares para conjuntos habitacionais. A primeira atuação de desfavelamento, em grande escala, ocorreu em 1967, com a transferência de famílias de ocupações irregulares para o Núcleo Habitacional Nossa Senhora da Luz, um conjunto de 2.100 casas, construído por intermédio da Companhia de Ha- bitação de Curitiba (COHAB-CT), com financiamento do Banco Nacional de Habitação (BNH).

Na década de 1970, surgiram núcleos de favelas e ocupações irregulares ainda mais intensos do que os assistidos até então. Em 1976, segundo a Política Municipal de Habitação e Habitação de Interesse Social (PMHHIS), foi realizado um levantamento em Curitiba que apontou a existência de 4.083 domicílios localizados em 35 ocupações irregulares. Dados do Instituto Paranaense de Desenvolvimento Econômico e Social (IPARDES), do Estado do Paraná, já apontavam que essa cifra era superior. Esse Instituto levantou, nos anos 1970, o número de 5.992 domicílios em áreas de ocupações irregulares, abrigando 33 mil habitantes, o que corresponde a 5,4\% da população (609.026 habitantes). A política habitacional aplicada nessa década não chegou a fazer efeito, já que apenas $13 \%$ da demanda foi beneficiada. Curitiba termina a década com 6.067 domicílios em 46 ocupações irregulares ou favelas, segundo dados do PMHHIS (Reis Júnior, 2012).

Com a extinção do BNH em 1986 e a consequente interrupção das linhas de financiamento para o setor, o número de domicílios em ocupações irregulares passou, de 7.716 em 1982, para 11.929, em 1987, segundo levantamento realizado pelo Instituto de Pesquisa e Planejamento Urbano de Curitiba (IPPUC).

A partir dos anos 1980, houve uma mudança nas políticas habitacionais do município de Curitiba. As políticas voltadas para a remoção de favelas diminuíram de dimensão. Elas foram substituídas pela política de venda de lotes urbanizados. É nesse período que se cria a Carta das Favelas, a qual descreve as intenções do poder público mediante as políticas habitacionais. Nessa década, famílias com renda de até três salários mínimos passaram a ser atendidas, preferencialmente, com lotes urbanizados, dotados de infraestrutura urbana mínima, com área de $160 \mathrm{~m}^{2}$. A prefeitura de Curitiba criou o Programa Plano dos Mil Lotes para Reassentamento (PROLOCAR), destinado às famílias de ocupações irregulares, com garantia de sua permanência em assentamentos em áreas públicas. 
Na década de 1990, a política habitacional toma outro rumo. A produção de conjuntos habitacionais e a oferta de lotes urbanizados se reduzem ainda mais, dando espaço ao processo de regularização fundiária. Como alternativa para a habitação de interesse social, foi gerado um Programa de Parcerias com a iniciativa privada para a produção de lotes urbanizados e apartamentos. Em 1992, foi desenvolvido o Plano de Ocupação da Região Sul, para atender aproximadamente a 22 mil famílias, mediante a oferta de lotes urbanizados e destinação de áreas específicas para prédios de apartamentos, com até quatro pavimentos.

Conforme o Censo Demográfico de 2000, o déficit habitacional de Curitiba era equivalente a $5 \%$, perfazendo 25.147 unidades. No critério de inadequação habitacional em relação ao adensamento, Curitiba apresentava 18.632 unidades, perfazendo $4 \%$ do total. A inadequação habitacional por acesso à infraestrutura abrangia 40.614 unidades, o equivalente a 9\% dos domicílios curitibanos (IBGE, 2000). Em 2000, o desafio era o de atender à crescente demanda habitacional. Nessa década, foi promulgada a nova Lei de Zoneamento, Lei Municipal de Curitiba ${ }^{\circ}$. 9800, de 03 de janeiro de 2000 e, em sequência, foi realizado o novo Plano Diretor de Curitiba, pela Lei $n^{\circ}$. 11266, de 16 de dezembro de 2004. A Lei de Zoneamento passou a contar com os denominados Setores Especiais de Habitação de Interesse Social, que delimitavam geograficamente as áreas populares e definiam seu uso e a ocupação com parâmetros diferenciados, seguindo a tendência das ZEIS implantadas em outras municipalidades.

Com atuação exclusivamente no setor de habitação de interesse social, para famílias de baixa renda, e prioritariamente no município de Curitiba, a COHAB-CT mantém um cadastro de pessoas interessadas em adquirir imóvel em seus empreendimentos, denominado Fila da COHAB, a qual apresentou um crescimen- to a partir de 2009, devido ao incremento na produção habitacional com a criação do programa Minha Casa, Minha Vida.

Quanto ao perfil de renda, entre as famílias inscritas na fila, nota-se que ele tem se mantido praticamente inalterado ao longo do período. As famílias com renda de até 3 salários mínimos constituem a maior parte dos inscritos, respondendo por cerca de $60 \%$ dos candidatos.

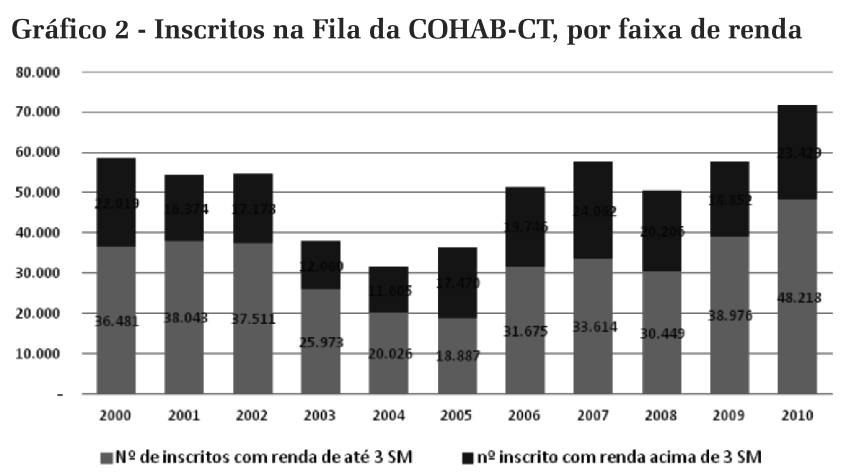

Fonte: Reis Junior, 2012

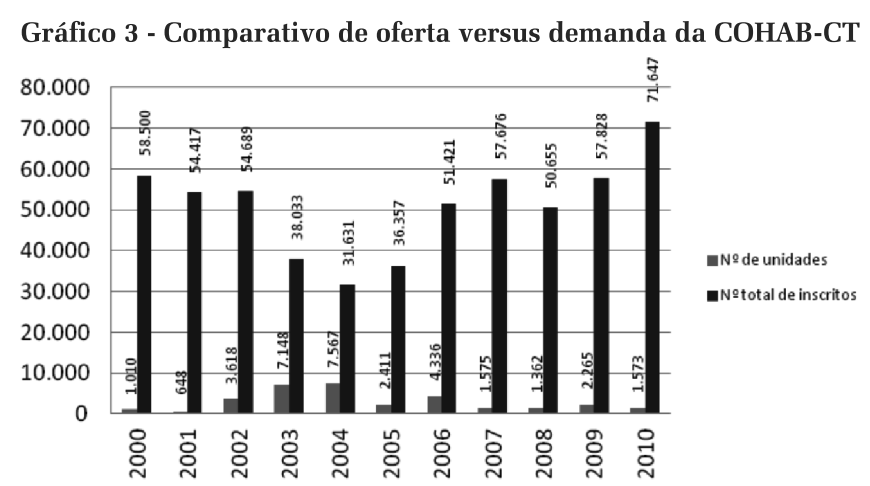

Fonte: Reis Junior, 2012

O cenário nacional reverbera no município de Curitiba, com o aumento do financiamento destinado à habitação de forma mais acentuada a partir de 2008 até 2010. Entretanto, apesar do crescente investimento de recursos em habitação e da criação do programa habitacional para atender a famílias de baixa renda (PMCMV), esse cenário ainda não se alterou.

\begin{abstract}
Dois elementos balizam, fundamentalmente, a nova política habitacional de Curitiba. O primeiro refere-se à adesão do município ao novo Sistema Nacional de Habitação de Interesse Soci-
\end{abstract}


al. O segundo diz respeito ao reconhecimento da articulação entre Plano Diretor e Plano de Habitação. No caso do município de Curitiba, a Lei 11.233, que instituiu o Plano Diretor em 20 de dezembro de 2004, apresentou, como um dos objetivos gerais da política de desenvolvimento urbano, a democratização do acesso à terra e à habitação, estimulando os mercados acessíveis às faixas de menor renda, bem como evitando o uso especulativo da terra como reserva de valor, de modo a assegurar o cumprimento da função social da propriedade.

O Plano de Habitação de Interesse Social e de Regularização Fundiária do Município de Curitiba foi consolidado pela COHAB-CT em dezembro de 2008. Esse plano foi firmado conjuntamente com os demais seis Planos Setoriais de Políticas Públicas, determinados pelo Plano Diretor do Município. O foco do Plano Municipal de Curitiba foi a elaboração do diagnóstico e a normatização da gestão para a aplicação e efetivação do Plano. Mais que cumprir as exigências formais e legais para a adesão ao Sistema Nacional de Habitação de Interesse Social, o Plano de Habitação de Interesse Social de Curitiba apresentou diretrizes e formulou estratégias para atender ao problema habitacional.

Curitiba também levou em consideração, para a execução de seu Plano de Habitação de Interesse Social, as recomendações da Política e do Plano Nacional de Habitação. Dentre as recomendações, apontava-se a política de locação social, que não foi abordada na nova política habitacional de Curitiba. Apesar da não existência de uma experiência organizada em um programa, ou a delimitação de uma proposta de locação social, destaca-se, contudo, que, desde 2008, a COHAB-CT disponibiliza imóveis que foram retomados por falta de pagamento do mutuário para o aluguel social. É uma ação bastante pontual, de escala ínfima (em 2008, foram 107; em 2009, foram 29; em 2010, foram 12), que não aparece entre os programas da Companhia e, aparentemente, atende apenas a famílias que habitam em áreas que passam por intervenções da Companhia e precisam de moradia transitória.

\section{DOMICÍLIOS ALUGADOS NO MUNICÍPIO DE CURITIBA}

\section{Localização dos imóveis alugados em Curitiba}

Os imóveis alugados concentram-se na região central do município de Curitiba e em subdistritos da região sul. O subdistrito central, correspondente à administração regional da Matriz, concentra o maior número de imóveis alugados, 23.570 , perfazendo $28,23 \%$ do total dos imóveis desse subdistrito e $19,32 \%$ do total do município. A administração regional do Portão congrega a segunda maior concentração de domicílios alugados no município. Essa administração conta com 21.541 domicílios alugados, ou seja, 20,51\% do total de domicílios desse subdistrito e $17,65 \%$ do total do município. Na mesma categoria de concentração, em relação ao total de domicílios por subdistrito, de $20 \%$ a $25 \%$, encontram-se também as administrações regionais do Boqueirão e Pinheirinho. A primeira, com 14.681 domicílios alugados, exibe $23,44 \%$ do total de domicílios desse subdistrito e $17,65 \%$ do total do município. A segunda, com 12.938 domicílios alugados, apresenta $21,08 \%$ do total de domicílios desse subdistrito e $10,60 \%$ do total do município.

Figura 2 - Domicílios alugados no município de Curitiba

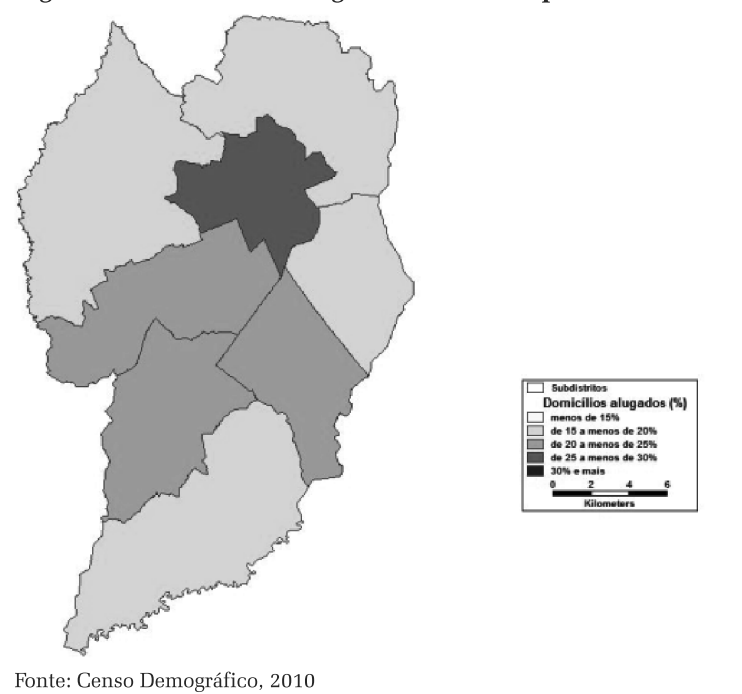


Tabela 1 - Domicílios por subdistrito

\begin{tabular}{l|c|cc}
\hline Subdistritos & $\begin{array}{c}\text { Domicílio particular } \\
\text { permanente }\end{array}$ & Alugados & (\%) \\
\hline 01 -Adm. Reg. da Matriz & 83454 & 23570 & 28,24 \\
\hline 02 -Adm. Reg. do Boqueirão & 62621 & 14681 & 23,44 \\
\hline 03 -Adm. Reg. do Cajuru & 67215 & 12606 & 18,75 \\
\hline 04 -Adm. Reg. da Boa Vista & 81118 & 15261 & 18,81 \\
\hline 05 -Adm. Reg. de Santa Felicidade & 62330 & 11185 & 17,94 \\
\hline 06 -Adm. Reg. do Portão & 105034 & 21541 & 20,51 \\
\hline 07 -Adm. Reg. Pinheirinho & 61374 & 12938 & 21,08 \\
\hline 08 -Adm. Reg. do Bairro Novo & 52753 & 10212 & 19,36 \\
\hline Total geral & 575899 & 121994 & 21,18 \\
\hline
\end{tabular}

Fonte: Censo Demográfico, 2010
Guaíra, Novo Mundo, Lindoia, Fanny, Capão Raso, Pinheirinho, Xaxim, Alto Boqueirão e Sitio Cercado. A grande maioria desses bairros pertence à Administração regional Matriz, Boqueirão, Pinheirinho e Portão. Além desses e em administrações regionais onde o percentual não era tão elevado, encontram-se os bairros de Santa Felicidade, São Braz, Bairro Novo e Capão da Imbuia.

As demais administrações regionais, Bairro

Novo, Boa Vista, Cajuru e San-

ta Felicidade apresentam de Figura 3 - Domicílios alugados no município de Curitiba

$15 \%$ a $20 \%$ do total de domicílios do subdistrito. Respectivamente, 19,36\%, 18,81\%, 18,75\%, 17,94\% domicílios alugados do total de domicílios permanentes.

A partir dos dados discriminados por subdistritos, é possível verificar quais são os que concentram maior percentagem de domicílios alugados. Com valores superiores a $30 \%$ de domicílios alugados encontram-se os bairros mais centrais, como Centro, Rebouças e São Francisco, todos perten- Fonte: Censo Demográfico, 2010
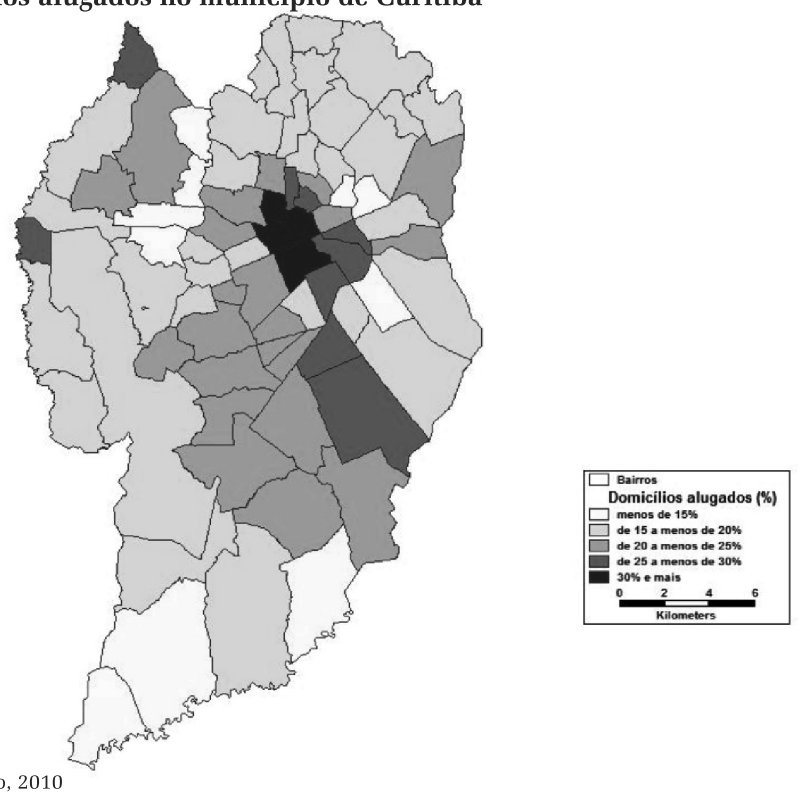

\section{Perfil atual do inquilino curitibano}

nal Matriz. Com 25\% a menos de 30\% de domicílios alugados, aparecem os bairros do Centro Cívico, Alto da Glória, Cristo Rei, Jardim Botânico e Prado Velho, todos pertencentes à Administração regional Matriz. Além desses, encontram-se também, na mesma categoria, os bairros de Lamenha Pequena e Riviera, pertencentes ao subdistrito de Santa Felicidade, bem como Hauer e Boqueirão, na Administração regional do Boqueirão. Com $20 \%$ a menos de $25 \%$ de domicílios alugados encontram-se os bairros do Bigorrilho, Mercês, Bom Retiro, Alto da XV, Água Verde, Vila Isabel, Fazendinha, Portão, a) Tipo de casa e infraestrutura

Em Curitiba, a madeira aparelhada está presente em 9,47\% dos domicílios. Ela é mais frequente nas casas alugadas (13,66\%) quenas próprias (8,25\%). A madeira aparelhada é material tradicional no sul do Brasil.

A proporção de população favelada em Curitiba é 9,32\% da população total. Em 2010, eram moradores em favelas 162 mil pessoas, residindo 
Tabela 2 - Material predominante por domicílios

\begin{tabular}{|c|c|c|c|}
\hline \multirow{2}{*}{ Material } & \multicolumn{2}{|c|}{ Domicílios ocupados } & \multirow{2}{*}{ Total } \\
\hline & Próprios & Alugados & \\
\hline Alvenaria com revestimento & 356111 & 98321 & 454432 \\
\hline Alvenaria sem revestimento & 20525 & 4398 & 24923 \\
\hline $\begin{array}{l}\text { Madeira apropriada para construção } \\
\text { (aparelhada) }\end{array}$ & 34192 & 16464 & 50656 \\
\hline Taipa revestida & 54 & 43 & 97 \\
\hline Taipa não revestida & 74 & 65 & 139 \\
\hline Madeira aproveitada & 2767 & 897 & 3664 \\
\hline Palha & 23 & 30 & 53 \\
\hline Outro material & 921 & 162 & 1083 \\
\hline Total & 414667 & 120380 & 535047 \\
\hline
\end{tabular}

Fonte: Censo Demográfico, 2010

em 8,12\% dos domicílios (46.806 unidades, num total de 576.211). Talvez a maior proporção de casas alugadas em madeira aparelhada indique que o estoque de habitação de aluguel seja mais antigo que o de casas próprias, dado que esse é um material tradicional.

O município é bem abastecido pela rede pública de água, com mais de 99\% de suas unidades ligadas à rede e contando com, pelo menos, 1 ponto de água interno ao domicílio. Praticamente não há diferença entre unidades próprias e alugadas. Em relação ao destino dos dejetos, a proporção de casas com destino inadequado é de $2,45 \%$, e é menor entre as alugadas. A coleta de lixo é abrangente, com menos de 1\% dos domicílios sem coleta. Apenas 3,52\% das unidades têm coleta em caçamba. Tanto casas próprias como alugadas têm energia elétrica, sendo que a proporção das alugadas com medidor coletivo é maior que as próprias: 9,75\% e $6,35 \%$, respectivamente. Esse pode ser um indicador de aluguel em casas de cômodos (ver Tabela 3).

Sobre a presença de utensílios domésticos, os dados de 2010 mostram que tanto as moradias próprias com as alugadas são bem servidas por objetos de consumo. O quadro relativo a Curitiba mostra que praticamente todas as unidades possuem TV em cores, não havendo diferença entre as alugadas e as próprias. O mesmo acontece em relação à geladeira. A lavadora de roupas é frequente em Curitiba, pois 87\% dos domicílios em Curitiba a possuem. O micro computador aparece em $66 \%$ das casas alugadas e em 70\% das próprias, majoritariamente ligado à internet. O carro para uso particular aparece em 54\% dos inquilinos e $72 \%$ dos proprietários.

b) Aspectos demográficos dos chefes defamília

Na Tabela 4, estão discriminados dados sobre sexo, faixa etária, cor, estado civil e migração relacionados aos chefes de família de moradias próprias e alugadas, em Curitiba.

Nota-se que:

- Cerca de 56\% dos chefes de família são homens. A proporção dos proprietários de sexo masculino é maior entre os proprietários que entre os inquilinos.

- Os chefes das casas alugadas são mais jovens que os das casas próprias: a idade média é de aproximadamente 49 anos para os proprietários e 39 anos para os locatários. A proporção dos chefes com até 39 anos vivendo em casas alugadas é de 58\%, bem superior à mesma proporção nas casas próprias, com 30\%, aproximadamente. De outro lado, entre os chefes idosos, com 60 anos e mais, temos 25\% de proprietários e apenas 9\% de inquilinos.

- A proporção de chefes de família pretos e pardos é de apenas 19\%. Essa proporção é maior nas casas alugadas.

- Em relação ao estado civil, o percentual de solteiros é o dobro entre os inquilinos, se comparado com o de proprietários. Os que vivem com companheiro ou companheira são mais frequentes entre os moradores de casa própria. Quando os inquilinos vivem em parceria, grande parte o faz em união consensual (44\%). A proporção de viúvos é maior entre os proprietários.

- O percentual de não nascidos em Curitiba é maior entre os inquilinos: 66\% do total. Os não nascidos no Paraná também têm maior probabilidade de morar em casa alugada. Em Curitiba, 11\% dos chefes migrantes são nascidos no Norte e no Nordeste, percentual um pouco maior entre os chefes inquilinos. 
Tabela 3 - Moradia e Infraestrutura (\%)

\begin{tabular}{|c|c|c|c|}
\hline Dados sobre a moradia & Próprios & Alugados & Total \\
\hline Proporção de alugados & \multicolumn{3}{|c|}{22,50} \\
\hline Aluguel médio ( em s.m.) & \multicolumn{3}{|c|}{1,09} \\
\hline \multicolumn{4}{|l|}{ TIPO DE CONSTRUÇÃO } \\
\hline alvenaria com revestimento & 85,88 & 81,68 & 84,93 \\
\hline alvenaria sem revestimento & 4,95 & 3,65 & 4,66 \\
\hline madeira aparelhada & 8,25 & 13,66 & 9,47 \\
\hline taipa, madeira, palha & 0,70 & 0,86 & 0,74 \\
\hline $\mathrm{n}^{\circ}$ médio de pessoas po rdomicílio & 3,45 & 3,09 & 3,42 \\
\hline $\mathrm{n}^{\circ}$ médio de cômodos por domicílio & 7,19 & 5,62 & 6,84 \\
\hline $\mathrm{n}^{\circ}$ médio de dormitórios por domicílio & 2,24 & 1,88 & 2,16 \\
\hline $\mathrm{n}^{\circ}$ médio de banheiros por domicílio & 1,69 & 1,28 & 1,60 \\
\hline $\mathrm{n}^{\mathrm{a}}$ médio de pessoas por cômodo & 0,48 & 0,55 & 0,50 \\
\hline $\mathrm{n}^{\circ}$ médio de pessoas por dormitório & 1,42 & 1,58 & 1,46 \\
\hline domicílios sem banheiro & 0,18 & 0,36 & 0,22 \\
\hline existência de sanitário ( entre os sem banheiro) & 68,67 & 88,33 & 75,93 \\
\hline \multicolumn{4}{|l|}{ INFRA-ESTRUTURA } \\
\hline \multicolumn{4}{|l|}{ Destino dos dejetos } \\
\hline rede & 93,07 & 94,03 & 93,28 \\
\hline fossa séptica & 4,36 & 3,93 & 4,26 \\
\hline outro & 2,57 & 2,05 & 2,45 \\
\hline \multicolumn{4}{|l|}{ Abastecimento de água } \\
\hline rede geral & 99,10 & 99,47 & 99,18 \\
\hline água encanada em pelo menos 1 cômodo & 99,06 & 0,11 & 99,07 \\
\hline \multicolumn{4}{|l|}{ Destino do lixo } \\
\hline coletado direto & 92,26 & 96,93 & 96,41 \\
\hline coletado em caçamba & 3,66 & 3,06 & 3,52 \\
\hline outro & 0,08 & 0,02 & 0,07 \\
\hline \multicolumn{4}{|l|}{ Energia elétrica } \\
\hline Sim, cia distribuidora & 99,80 & 99.93 & 99,83 \\
\hline Sim, outra fonte & 0,19 & 0,06 & 0,16 \\
\hline Não tem & 0,02 & 0,01 & 0,02 \\
\hline tem energia, medidro coletivo & 6,35 & 9,75 & 7,11 \\
\hline tem energia mas sem medidor & 0,73 & 1,13 & 0,82 \\
\hline \multicolumn{4}{|l|}{ UTENSÍLIOS DOMÉSTICOS } \\
\hline rádio & 92,10 & 84,21 & 90,33 \\
\hline TV & 98,37 & 98,16 & 98,33 \\
\hline lavadora de roupas & 89,33 & 78,57 & 86,91 \\
\hline geladeira & 99,38 & 97,65 & 98,99 \\
\hline telefone celular & 91,08 & 95,72 & 92,12 \\
\hline telefone fixo & 80,44 & 54,54 & 74,61 \\
\hline micro computador & 70,30 & 64,55 & 69,01 \\
\hline entre os que tem micro, ligação á internet & 88,65 & 82,84 & 87,43 \\
\hline motocicleta uso particular & 12,46 & 11,20 & 12,17 \\
\hline carro uso particular & 72,33 & 53,66 & 68,13 \\
\hline
\end{tabular}

- O tempo médio do migrante no Estado do Paraná é menor entre os inquilinos: 13 anos no estado e 11 anos em Curitiba. A migração para Curitiba é mais recente (22 anos no município e 23 no Estado). Mais de 7\% dos proprietários e 3,4\% dos locatários tiveram como moradia anterior um país estrangeiro. O perfil migratório de Curitiba é bem específico: 5,72\% e 5,57\% dos migrantes vêm países asiáticos, como China e Japão respectivamente; da Europa, 9,49\% vêm da Alemanha e 11,99\% de Portugal; da América Latina, 9,22\% vêm da Argentina e 5,01\% do Paraguai. 
Tabela 4 - Demografia de Curitiba: relação entre o chefe de família de moradias próprias e alugadas em 2010 (\%)

\begin{tabular}{|c|c|c|c|}
\hline \multirow{2}{*}{$\begin{array}{l}\text { DEMOGRAFIA } \\
\text { Variável }\end{array}$} & \multicolumn{3}{|c|}{ Domicílios Curitiba } \\
\hline & Próprios & Alugados & Total \\
\hline \multicolumn{4}{|l|}{ Sexo do chefe } \\
\hline homens & 55,93 & 44,89 & 55,92 \\
\hline \multicolumn{4}{|l|}{ Idade do chefe } \\
\hline idade média em anos & 48,95 & 38,86 & 46,68 \\
\hline ate 39 anos & 29,61 & 58,03 & 36,01 \\
\hline 40 a 59 anos & 45,42 & 32,91 & 42,60 \\
\hline 60 e mais & 24,97 & 9,06 & 21,39 \\
\hline \multicolumn{4}{|l|}{ Cor do chefe } \\
\hline$\%$ pretos + pardos & 17,43 & 23,77 & 18,86 \\
\hline \multicolumn{4}{|l|}{ Estado civil } \\
\hline solteiros & 22,51 & 45,40 & 27,66 \\
\hline vivem com companheiro(a) & 64,81 & 56,25 & 62,88 \\
\hline dos que vivem com parceiro/a em união consensual & 22,60 & 47,44 & 27,60 \\
\hline separados/divorciados & 11,88 & 12,70 & 12,07 \\
\hline viúvos & 11,27 & 5,66 & 10,01 \\
\hline \multicolumn{4}{|l|}{ Migração } \\
\hline nasceu e sempre morou em Curitiba & 34,40 & 25,36 & 32,37 \\
\hline não nasceu em Curitiba & 59,15 & 66,23 & 60,74 \\
\hline nasceu e sempre morou no Paraná & 47,44 & 26,78 & 42,37 \\
\hline não nasceu na Paraná & 42,09 & 51,37 & 44,37 \\
\hline migrantes nascidos no exterior & 4,61 & 2,87 & 4,11 \\
\hline migrantes nascidos no Norte e Nordeste & 10,05 & 12,64 & 10,80 \\
\hline tempo médio de moradia do migrante em Curitiba em anos & 26,64 & 11,24 & 22,12 \\
\hline tempo médio de moradia do migrante no Paraná em anos & 29,91 & 13,53 & 23,39 \\
\hline \multicolumn{4}{|l|}{ Local de moradia anterior a Curitiba } \\
\hline estrangeiro & 7,07 & 3,40 & 5,60 \\
\hline Norte + Nordeste & 5,51 & 7,48 & 6,61 \\
\hline
\end{tabular}

c) Aspectos socioeconômicos dos chefes de família

Alguns itens censitários relacionados a escolaridade, trabalho, renda, previdência social e local de trabalho permitiram uma caracterização dos chefes de família de Curitiba moradores de casas próprias e alugadas (ver Tabela 5).

\section{Nota-se:}

- Quase a totalidade dos chefes de família de Curitiba sabe ler e escrever: 98\%. E 33\% dos chefes têm mais de12 anos de escolaridade. A diferença entre proprietários e locatários favorece, de forma tênue, os proprietários.

- A proporção de chefes de família que se declararam desocupados na última semana de julho de 2010 foi de 31,48\%. O percentual é menor entre os inquilinos (23\%) que entre os proprietários (34\%). E entre os motivos para o não trabalho, a proporção dos afastados foi maior entre os inquilinos.

- A estrutura ocupacional dos chefes de família mostra maior proporção de proprietários entre as ocupações superiores (29,72\%) do que entre os locatários (24,98\%). Inversamente, entre os trabalhadores não especializados, a proporção de inquilinos é maior (10,32\%, enquanto que, entre os proprietários, era 7,78\%). A categoria modal, para os dois subconjuntos, foi a dos trabalhadores de serviços e comércio (15\% entre proprietários e 17,5\% entre inquilinos).

- A informalidade é maior entre os inquilinos. A maioria dos chefes de Curitiba não contribui para a Previdência social (59\%), proporção maior entre os inquilinos. E quase 335 dos chefes de família proprietários usufruem de pensão, aposentadoria e (ou) programa de transferência de ren- 


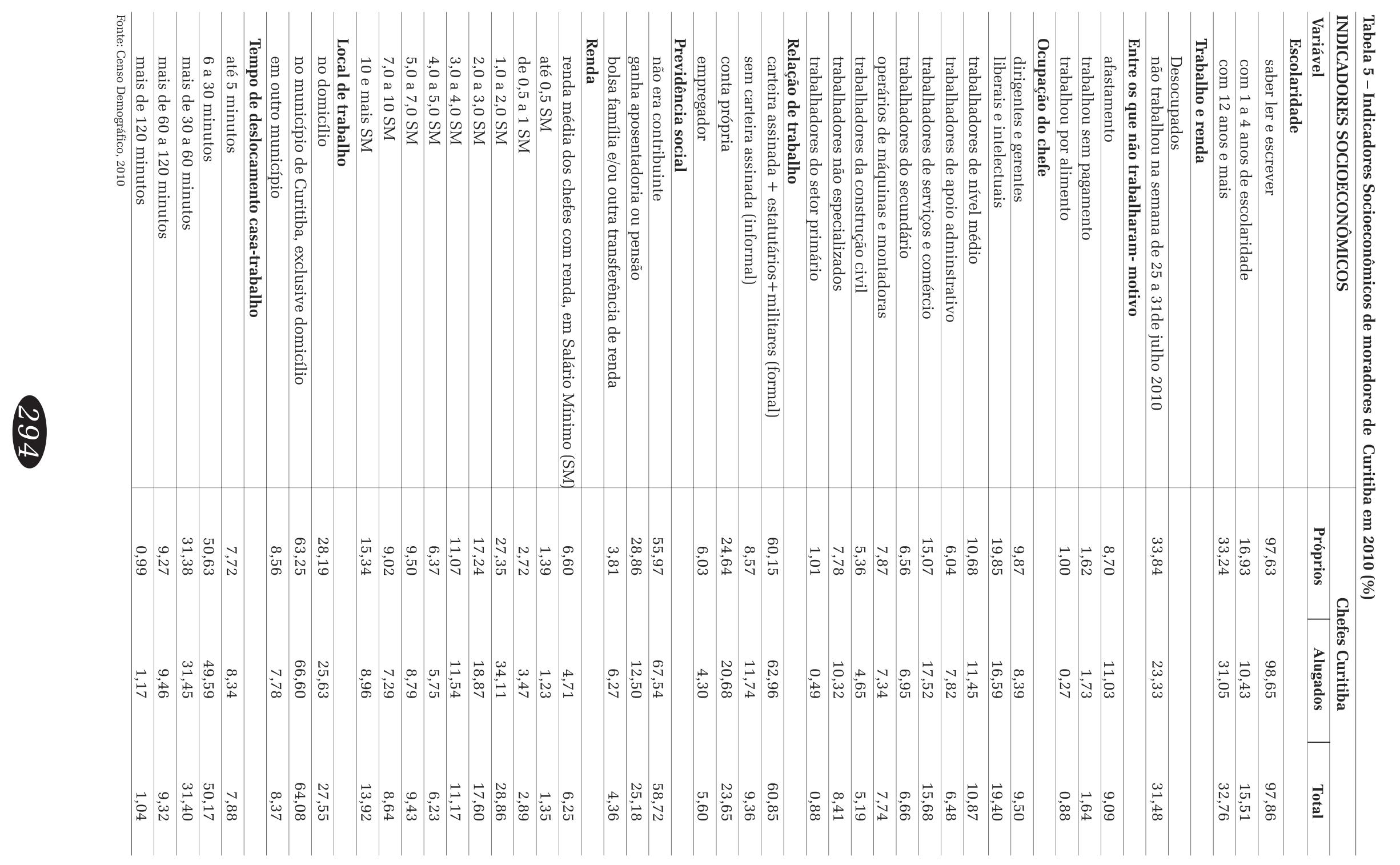


da, para 19\% dos inquilinos.

- A renda média dos chefes com renda é maior entre os proprietários (6,60 salários mínimos) que entre os inquilinos (4,71 salários mínimos). A renda modal situa-se entre 1 e 2 salários mínimos, onde estão $27,35 \%$ dos proprietários e $34,11 \%$ dos inquilinos.

- A proporção dos trabalhadores que usam o próprio domicílio como local de trabalho é pouco maior entre os proprietários (28\%) que entre os inquilinos (26\%). A proporção de chefes que trabalham em outros municípios foi de 8,37\%.

- A mesma proporção de inquilinos e de proprietários utiliza até 30 minutos para o deslocamento entre casa e trabalho: $58 \%$. Não se nota grande diferença nos tempos de deslocamento entre inquilinos e proprietários.

O perfil do locatário de Curitiba mostra que ele é alfabetizado, e 31\% apresentam 12 anos e mais de escolaridade; $77 \%$ era ocupado, e a proporção de trabalhadores do comércio e serviços $(17,5 \%)$ era praticamente equivalente à dos liberais e intelectuais (16,6\%). A maioria dos inquilinos é empregada no setor formal (63\%), mas não era contribuinte da previdência (685). A renda média dos inquilinos foi de 4,71 salários mínimos, e a renda modal situou-se entre 1 e 2 salários mínimos. Cerca de $26 \%$ trabalhavam no próprio domicílio e $58 \%$ usavam até 30 minutos para o deslocamento entre casa e trabalho.

\section{CONSIDERAÇÕES FINAIS}

Os poderes públicos vêm retomando a questão da habitação de interesse social com a introdução da Política Nacional de Habitação de Interesse Social e a obrigatoriedade de formulação de planos estaduais e municipais para acesso ao Fundo Nacional de Habitação de Interesse Social. Os planos que começam a ser elaborados vêm consolidar um novo entendimento da política habitacional, que deixa de ser exclusivamente urbana e integra o espaço rural na pauta de discussão e que entende a necessidade de incorporar não somente a cons- trução de unidades habitacionais à cidade, mas também integrá-las, de forma a garantir qualidade de vida aos moradores.

A elaboração de políticas municipais é uma conquista fundamental para os municípios, que, apesar de terem autonomia para tal a partir de 1988, com a Constituição Federal, e de 1989, com a Constituição Estadual, vêm fortalecendo essa autonomia por meio de seus Planos Diretores e Planos Municipais de Habitação de Interesse Social.

A falta da construção e consolidação de políticas municipais consistentes faz com que a política fique frágil, tendo em vista a formação do recente Plano Municipal de Habitação de Interesse Social de Curitiba. Há, sem dúvida, uma falta de definição de proposições efetivas de gestão e de planejamento participativo. É um equívoco não construir políticas integradas que visem à melhoria das condições de moradia no município.

O comportamento demográfico da Região Metropolitana demonstra também claramente a importância que a demanda por habitação é intermunicipal e metropolitana, oriunda do processo de metropolização, mas as soluções continuam independentes de seu contexto regional e metropolitano, pois são propostas isoladas, fora dessa leitura.

Os investimentos em locação social jamais foram efetivamente tratados ao longo das políticas habitacionais no município de Curitiba. Com o apontamento do Plano Nacional de Habitação para essa perspectiva habitacional, o município de Curitiba poderia ampliar as práticas habitacionais, tendo em vista o quadro de domicílios alugados.

O Plano Local de Habitação de Curitiba poderia ter apresentado instrumentos para a efetivação da locação social do município. Contudo essa prática ainda não aparece como objeto dentre as ações habitacionais do município.

Compreender a circunstância e as condições dos imóveis alugados em Curitiba, que se concentram especialmente na região central do município, é extremamente importante para a construção de uma política de locação social. Destacam-se, no município, o número de imóveis nes- 
sas condições e as condições de renda dos moradores. Analisar as condições demográficas, socioeconômicas, de moradia e infraestrutura permitem um novo olhar sobre as características dos domicílios alugados.

Para trabalhar e redefinir as novas dinâmicas de Curitiba, carece integrar os territórios e construir novas metodologias de caracterização das moradias, das dinâmicas demográficas e socioeconômicas para os Planos Locais de Habitação de Interesse Social, Caso contrário, continuarse-á construindo políticas avulsas e que não incorporam as transformações e as necessidades habitacionais efetivas.

Recebido para publicação em 15 de dezembro de 2013 Aceito em 02 de março de 2014

\section{REFERÊNCIAS}

ALBUQUERQUE, Aline. A questão habitacional em Curitiba: o enigma da "cidade modelo". 2007. Dissertação (Mestrado) - FAU da Universidade de São Paulo. São Paulo: FAU-USP, 2007.

ALFONSIN, B.; FERNANDES, E. Direito à moradia e segurança da posse no estatuto da cidade. Diretrizes, instrumentos e processos de gestão. Belo Horizonte: Fórum 2006.

BAENINGER, R. Redistribuição espacial da população e urbanização: mudancas e tendências recentes. In: GONÇALVES, M. F.; BRANDÃ̃, C. A.;GALVÃO, A. C. (Org.) ㄱ. regional. São Paulo: UNESP, 2003. p.271-288.

BONDUKI, N. Política habitacional e inclusão social no

- Brasil: revisão histórica e novas perspectivas no governo

I Lula Revista Eletrônica de Arquitetura e Urbanismo, Sã

$\sum$ Paulo, n.1, p.70-104, 2008. Disponível em: http:// ล̊ www.usjt.br/arq.urb/numero_01/artigo_05_180908.pdf. จ Acesso em: jan. 2011.

BRASIL. Ministério das Cidades. Plano Nacional de Habitação. Disponível em: http://www.cidades.gov.br/secretarias-nacionais/secretaria-de-habitacao/politicanacional-dehabitacao/4PoliticaNacionalHabitacao.pdf. Acesso em: 10 abr. 2012 .

. Sistema Nacional de Habitação. Disponível em: http://www.cidades.gov .br/ secretarias-nacionais/secretaria-de-habitacao/politicanacional-de-habitacao/4Politica Nacional Habitacao.pdf. Acesso em: 21 fev. 2014.

BREMBATTI, K. Ritmo cai, mas região de Curitiba é a que mais vai crescer até 2020. Gazeta do Povo, Curitiba, 20 ago. 2007. p.3.

BURSZTYN, M. A exclusão e o local: tempos e espaços da diversidade social. In: DINIZ, C. C. (Org.) Políticas de desenvolvimento regional: desafios e perspectivas à luz das versidade de Brasília, 2007.
CASTRO, Cláudia. A habitabilidade urbana como referencial para a gestão de ocupações irregulares. 2007. Dissertação (Mestrado) - Pós-Graduação de Gestão Urbana da Pontíficia Universidade Católica do Paraná. Curitiba, 2007.

IBGE. Instituto Brasileiro de Geografia e Estatística. Censo Demográfico, 2000. Rio de Janeiro: 2000.

. Censo Demográfico, 2010. Rio de Janeiro: 2010.

IPARDES. Instituto Paranaense de Desenvolvimento Econômico e Social. Problemas habitacionais dos assentamentos precários urbanos na Região Metropolitana de Curitiba. Relatório I. Curitiba: 2009.

. Leituras Regionais. Mesorregião Geográfica Metropolitana de Curitiba. Curitiba: 2004.

IPPUC. Instituto de Pesquisa e Planejamento Urbano de Curitiba. Plano Diretor de Curitiba. Curitiba: 2004.

. Instituto de Pesquisa e Planejamento Urbano de Curitiba. Ocupações irregulares no município de Curitiba: situação de risco. Curitiba: 1999-2000.

Plano Municipal de Habitação de Interesse Social de Curitiba. Disponível em: http:/www.cidades.gov.br/ secretarias-nacionais/secretaria-dehabitacao/site/banco-dereferencia /bahia/salvador. Acesso em: 01 fev. 2014.

MOREIRA, T.; LEONELLI, G.; NASCIMENTO NETO, P. Respostas municipais ao problema de habitação social na Região Metropolitana de Curitiba. Revista Oculum Ensaios, Campinas, n.5, 2012.

MOREIRA, T.; SCHUSSEL, Z. Os Planos Municipais de Habitação e seus Processos Participativos: Curitiba, Salvador e Santo André. In: CONGRESSO BRASILEIRO,3.,/ CONGRESSO IBERO AMERICANO DE HABITAÇÃO SOCIAL: CIENCIA E TECNOLOGIA,2., 2010 , Florianópolis. Anais... Florianópolis: 2010.

MOREIRA, T.; SCHUSSEL, Z.; SCHUSSEL, S. Plano de habitação de interesse social: instrumento da nova Política Habitacional Brasileira. In: MOREIRA, Tomás; KOZICKI, Katya; LOPES, Fabiane; NETTO BESSA, Bueno; ALMEIDA, Gabriel Gino (Org.) Espaços e suas ocupações: debates sobre a moradia e a propriedade no Brasil contemporâneo. Campinas: Ed. Russel, 2010. p.214-234.

REIS JUNIOR, J. M. C. A habitação de interesse social e o comportamento do mercado imobiliário formal de baixa renda: caso de Curitiba no período de 2001 a 2010. 2012. Dissertação (Mestrado) - Pós-Graduação de Gestão Urbana da Pontíficia Universidade Católica do Paraná. Curitiba: PPGTU, 2012. 


\section{HOUSING POLICY AND SOCIAL RENT IN CURITIBA}

\section{Tomás Antonio Moreira}

Based on census data, this article analyzes the social housing policy in the metropolitan area of Curitiba from 2000 to 2010 . Data on migratory movements show that, although this region attracts the largest number of migrants in the state, the capital city is no longer the destination of the majority. With less infrastructure, São José dos Pinhais and Colombo are the cities attracting most migrants currently. The study focuses on housing for low-income families, particularly social rend, and presents the situation of housing units, the available infrastructure, and the demographic and socio-economic aspects household heads. Data interpretation is contextualized using a historical review of housing policies promoted by the state since the 1970's.

KEYwORDS: Housing policy. Social rent. Migratory movements. Metropolitan area of Curitiba.

\section{POLITIQUE DU LOGEMENT ET LOGEMENTS SOCIAUX À CURITIBA}

\section{Tomás Antonio Moreira}

À partir des données du recensement l'article fait l'analyse de la politique des logements sociax dans la Région Métropolitaine de Curitiba entre 2000 et 2010. Les données concernant les flux migratoires révèlent que bien que cette région attire un plus grand nombre de migrants au niveau de l'état, la majorité ne va cependant pas vers la capitale. Les villes de São José dos Pinhais et Colombo, dotées de moins d'infra-structures, constituent un pôle d'attraction plus important. En mettant l'accent sur l'habitat destiné aux familles ayant peu de revenus, sur le loyer social en particulier, on y présente les conditions qu'offrent les habitations, l'infra-structure existante et les aspects démographiques et socio-économiques des personnes de référence des ménages. La lecture des données est remise en contexte grâce à une récupération historique des politiques du logement promues par l'Etat depuis les années 1970.

Mots-CLÉs: Politique du logement. Logements sociaux. Flux migratoires. Région Métropolitaine. Curitiba.

Tomás Antonio Moreira - Professor Titular da Pontifícia Universidade Católica de Campinas. Membro do corpo docente do Programa de Pós Graduação em Urbanismo e da Faculdade de Arquitetura e Urbanismo. Ph.D. em Estudos Urbanos pela Université du Québec à Montréal. Editor-chefe da Oculum Ensaios - Revista de Arquitetura e Urbanismo do Programa da PUC-Campinas. Tem experiência na área de planejamento e gestão urbana e regional, atuando principalmente nos temas de políticas públicas habitacionais e fundiárias, instrumentos urbanísticos, urbanização, mobilidade urbana, governança e participação social. 
